\title{
Business Intelligence and Performance Management
}

George Cosmin TĂNASE

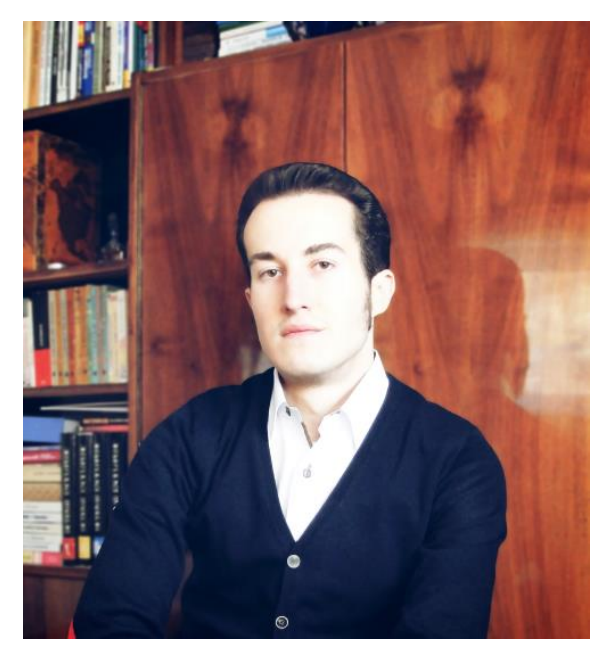

\begin{abstract}
Globalisation, volatile markets, legal changes and technical progress have an immense impact on business environments in most industries. More and more IT is deployed to manage the complexity. As a result, companies and organisations have to handle growing volumes of data which have become a valuable asset. The ability to benefit from this asset is increasingly essential for business success. Therefore, fast storage, reliable data access, intelligent information retrieval, and new decision-making mechanisms are required. Business Intelligence (BI) and Performance Management (PM) offer solutions to these challenges.
\end{abstract}

Keywords: Data storage; Relevant knowledge; Analytic tools; Communication; Target values; Operational level; Business strategy; Holistic approach; Enterprise Performance Management

JEL Classification: C81, C82, M15, M21, G10, Q55

\section{Current and Future Challenges}

During the $21^{\text {st }}$ century business environments have become more complex and dynamic than ever before. Companies operate in a world of change influenced by globalisation, volatile 
markets, legal changes, and technical progress. More and more IT is deployed to manage the complexity. As a result, growing volumes of data, for instance, provided by CRM systems, web shops or sensor technologies, have to be handled. Therefore, fast storage, reliable data access, intelligent information retrieval, and automated decision-making mechanisms, all provided at the highest level of service quality, are required. Successful enterprises are aware of these challenges and efficiently respond to the dynamic environment in which their business operates. Business Intelligence (BI) and Performance Management (PM) offer solutions to the challenges mentioned above and provide techniques to enable effective business change. The corresponding instruments allow transparency of processes and their results on all management levels. Based on this information, action can be taken as fast as possible in the case of sudden market changes or critical developments. Meanwhile, companies in many industries, including technology suppliers, have realised this point and act as players in the fields of BI and PM. Thus, it is not surprising that the IT environment has changed dramatically over the last decades, both in terms of new business as well as in soft- and hardware requirements.

BI and PM are now well established and an important field for researchers as well as for professionals in all industries. Whether activities in this field are successful or not depends on certain prerequisites. It is important to address aspects from different points of view, which cover the following issues:

- BI/PM concepts to support business analytics, strategy and management

- BI/PM applications to contribute to business development

- methodologies

- technologies

\section{Business Intelligence (BI)}

In 1996 the Gartner Group stated: "Data analysis, reporting, and query tools can help business users wade through a sea of data to synthesize valuable information from it - today these tools collectively fall into a category called 'Business Intelligence”. Consequently, leading companies in the field of management support environment adopted the term and subsumed all their tools for Data Warehouses (DWH), Data Marts (DM), Online-Analytical Processing (OLAP), data mining, etc. under the umbrella term Business Intelligence. Hence, in the early days the term BI was only used to describe the heterogeneous conglomerate of isolated tools, supporting various tasks of managers. It took years to establish a common understanding of BI in research and practice. Meanwhile the various approaches merged into a common, rather inclusive understanding in the community that heavily focuses on aspects of integration and consistency. Based on this, BI is 
defined here as "an integrated, company-specific, IT-based total-approach for managerial decision support".

From an application-oriented, logical perspective, a typical BI architecture consists of three layers. These three layers are based on operational sources, like Supply Chain Management (SCM), E-Procurement Systems, Enterprise Resources Planning (ERP) Systems, Customer Relationship Management (CRM), and external sources. The systems of the Data Support Layer are fed by ETL processes (extraction-transformation-loading). Data Support Layer The data support layer is responsible for storing transformed and harmonised, structured and unstructured data for decision support. Relevant data storing systems for unstructured data are document and content management systems. Structured data is stored in operational data stores (ODS), data warehouses (DWH) and data marts, whereas ODS are reservoirs for transactional data, which are often stored real-time without complex historisation routines. DWHs are data management systems for integrated, non volatile, time-variant and subjectoriented data. Bigger DWH "hub-and-spokearchitectures" have data marts, which are smaller data collections extracted from Core-DWHs, often based on multidimensional data models to support department-oriented ad-hoc reporting.

Information Generation, Storage, Distribution Layer This layer provides functionality to analyse structured data or unstructured content and supports the distribution of relevant knowledge. The analytical functionality of this layer includes OLAP and data mining, in addition to functionality to generate (interactive) business reports, ad-hoc analysis, or to implement performance management concepts, like the Balanced Scorecard or Value Driver Trees. For the distribution of knowledge, tools from Knowledge Management and CSCW domains are used, e.g. workflow support or tools for information retrieval. Information Access Layer The information access layer offers the user convenient access to all relevant BI functions in an integrated environment - within the confines of defined user roles and user rights. Usually, the access layer is realised with some sort of portal software, which provides a harmonised graphical user interface. In initial discussions on enterprisewide BI approaches, practitioners and researchers propagated the development of a single enterprisewide reservoir with harmonised data for decision support. It was argued that only in this way "a single point of truth" could be established, which is able to guarantee consistent support for all managerial decisions made in companies. In recent years, the debate became more controversial. It is now argued that BI approaches have to support heterogeneous decisions in strategic business units with often highly specific information needs. Besides, the field of BI is expanding and is being vitalised by new concepts and technologies in the area of data gathering and process support. Since the requirements of the primary and secondary business and production processes involved often differ fundamentally, it becomes clear that monolithic company solutions can not lead to satisfactory 
solutions. Modern Business Intelligence solutions therefore normally consist of a set of different interacting data storing systems, diverse ETL procedures, domain-specific data granularities, adequate analytic tools, and appropriate BI process models, in order to meet all of the challenges for effectively supporting processes.

\section{Performance Management (PM)}

Since a few years, the term Performance Management (PM), which partially overlaps with $\mathrm{BI}$, attracts attention in science as well as in industry. According to an independent multivendor study of the Business Application Research Center (BARC) more than $80 \%$ of all surveyed companies which were from different countries and industries have recognised the necessity to improve their PM processes. They claim a growing need for integrated technology platforms which support PM. Subsequently, it is not surprising that the Gartner Group predicts a significant and growing demand for PM solutions. Unfortunately, there is no clear definition of PM and its different variants. In the literature, a huge variety of PM definitions can be found, for example. Sharma states that PM is based on "the process of assessing progress towards achieving predetermined goals". It involves "the relevant communication and action on the progress achieved against these predetermined goals". In contrast to that, Lebas calls PM a philosophy. It is obvious that these definitions differ in scope. Both remain a little bit imprecise. Geishecker's and Rayner's interpretation is more precise. They define PM as methodologies, metrics, processes and systems which are used to monitor and manage business performance. If the focus is set on PM in the context of enterprises, the terms Corporate Performance Management (CPM) or Enterprise Performance Management (EPM) can be used. They are subsets of PM. The term CPM is widespread in science as well as in industry. EPM is used by well-known software companies, such as Oracle or SAP. Because EPM and CPM exclude public institutions and non-profit organisations by definition, the term Business Performance Management (BPM) can be used in a more general context.

While the operational level deals with aspects of monitoring, controlling and the optimisation of work processes, the strategic level defines business objectives and strategic Key Performance Indicators (KPIs). The starting point is the analysis of the business and the subsequent definition of business objectives. Based on the business objectives, strategic KPIs are derived. They influence the process design and the definition of process-oriented indicators. It is important to align processes with strategic KPIs by defining operational KPIs. Operational KPIs periodically quantify the performance on the operational level. Compared to strategic KPIs their aggregation level is lower.

On the operational level, process performance has to be planned. In the case of automated processes, process execution can be monitored by business activity monitoring (BAM) tools. Of course, it is also possible to collect or add data manually. The data collected, which is processed by 
performance reporting tools, allows analyses of the process performance in terms of the objectives. The key data from the operational layer is monitored and analysed on a regular basis. The analyses make the actual performance transparent. Indicators, such as "average operational hours per day", are compared with planned values in order to identify possible issues in process execution. If the benefits overcome the effort, for example, if it is very important to recognise manufacturing problems as early as possible, real-time data monitoring can be desirable. BI components, as well as PM tools, can be used for further analyses. Abnormalities in the indicators denote issues which, for instance, can be caused by inefficient processes or exceptional market fluctuations. As a result, action can be taken, such as changing the process or revising the goals. In the ideal case, potential problems are avoided and identified before they arise. The positive or negative effects of those adjustments are measured in the next iteration, and a new cycle starts. Of course, the results which are achieved on the operational level have an impact on the strategic level. Aggregated data is used to analyse business or rather the corresponding strategic KPIs, regularly. Deviations of current parameters from target values can indicate alignment problems on the operational level or an inadequate business strategy. As a consequence, for instance, an adjustment of business objectives on the strategic level can be triggered. This can result in a complete redesign of business processes. The impacts on the operations are measured and analysed again by means of figures. Thus, the loop is closed and the strategic level is linked to the operational level.

The information generation, storage, and distribution layers of BI architectures include functionality to implement PM concepts and its components, such as Balanced Scorecards. In this context, PM can be seen as an extension of BI. While BI applications are focused on the automated collection of data and the analyses by means of tools, such as data mining or OLAP, PM focuses on the process of systematic monitoring and on the control of business objectives on different management levels. The intention is to achieve sustainable success by means of continuous process improvements in terms of the company's strategy.

\section{Conclusions}

$\mathrm{BI}$ and PM offer a rich set of concepts and tools to efficiently master the challenges which are caused by the dynamic environment of companies and organisations. The successful application of BI and PM requires a common understanding of all of the parties involved. The application-oriented view includes:

- the data support layer,

- the information generation, storage, and distribution layer,

- and the information access layer. 
Afterwards, different interpretations of PM were analysed. It was shown that PM is based on the idea of the closed-loop approach. Closed-loops can be established on different management levels and should be linked to achieve full transparency of processes and their results. This enables companies and organisations to respond quickly to current developments. The process-oriented view of PM contributes to continuous improvements in terms of the strategic goals, and the holistic approach is an important requirement for sustainable success. By means of integrated BI and PM components, the complete information chain, ranging from data supply to decision-making, can be supported and automated to a great extent. Thus, the growing amount of data can be processed efficiently. They are a valuable asset for companies and organizations. The ability to benefit from this asset is more and more essential for business success in competitive environments.

At the beginning of February 2015 Gartner's Analyst Neil Chandler underlined that a primary investment focus in 2015 continues to be "Business analytics", an umbrella term for analytics, business intelligence and performance management which organizations should rearchitect. He argued that IT leaders of analytic initiatives must adapt to deliver increased business value because processes, approaches and platforms are rapidly evolving, and in order to optimize decisions and manage performance are required leadership and organizational competencies to use information and analysis accordingly. Allow us to remember, within the context of the well-known Gartner's “Business Intelligence and Performance Management Key Initiative Overview”, that the same Gartner's Analyst Neil Chandler showed on 22 April 2014 how business value is continuing to be driven by the business intelligence and performance management. And in order to connect IT-related initiatives with business strategy and business transformation, it was recommended to execute business intelligence and performance management initiatives by using a structured approach (strategize and plan; develop governance; drive change management; execute; measure and improve).

On the other hand, it is worth mentioning the challenges faced by CFOs from the point of view of transforming their finance organizations and generating value for the business, by adequately using the Enterprise Performance Management (EPM) processes. According to its recent survey, Oracle identified seven trends (EPM embraces the cloud, speed is key; mobile goes beyond convenience to strategic; Big Data is creating a new signal for finance; modern planning practices are becoming a reality; detailed costing practices are needed to stay in the game or get ahead; finance departments need literacy as well as numeracy; organizations are not realizing the wider benefits of enterprise data governance), concluding with all that's needed now (while driving digital transformation): predictive, data-driven analysis, continuous planning and budgeting, real-time decision making. 


\section{References}

[1] Anandarajan, M., Anandarajan, A., Srinivasan, C.A.: Business Intelligence Techniques. Springer, Berlin (2004)

[2] Baars, H., Kemper, H.G.: Management support with structured and unstructured data-an integrated business intelligence framework. Inf. Syst. Manag. 25(2), 132-148 (2008)

[3] BARC: Performance Management-Aktuelle Herausforderungen und Perspektiven (2009).

[4] Becker, D., Brunner, J., Bühler,M., Hildebrandt, J., Zaich, R.: Value-Based Performance Management. Gabler, Wiesbaden (1999)

[5] Dinter, B., Bucher, T.: Business performance management. In: Chamoni, P., Gluchowski, P. (eds.) Analytische Informationssysteme, 3rd edn., pp. 23-50. Springer, Berlin (2006)

[6] Eddy, N.: BI, Performance management software market surpassed 12B in 2011.

[7] Geishecker, L., Rayner, N.: Corporate performance management: BI collides with ERP. Research note SPA 14-9282, Gartner, Inc., December 17 (2001)

[8] Hoffmann, O.: Performance management. Diss., Bern et al. (1999)

[9] Inmon, W.H.: Building the Data Warehouse, 4th edn. Wiley, New York (2005)

[10] Kemper, H.G., Baars, H.: Business Intelligence und Competitive Intelligence. HMD, Prax. Wirtsch.inform. 43(247), 7-20 (2006)

[11] Chandler, N. - Agenda Overview for Analytics, Business Intelligence and Performance Management, 2015, 06 February 2015, Retrieved from:

https://www.gartner.com/doc/2978917/agenda-overview-analytics-business-intelligence, $8 / 17 / 2015$

[12] Chandler, N. - Business Intelligence and Performance Management Key Initiative Overview, 22 April 2014, Retrieved from:

https://www.gartner.com/doc/2715117/business-intelligence-performance-managementkey, 8/17/2015

[13] Oracle - Enterprise Performance Management Top Trends for 2015, Retrieved from: http://www.oracle.com/us/solutions/ent-performance-bi/business-intelligence/epm-toptrends-for-2015-2441101.pdf, 8/17/2015 